\title{
O Mito da Revolução, Guerreiro Ramos e o Golpe de 1964
}

João Carlos Nogueira ${ }^{1}$

Reafro Brasil, Estado, Brasil

E-mail: jcnogueira13@gmail.com 


\section{Resumo}

Neste artigo, vamos perseguir a hipótese em algumas dimensões já exploradas no campo da Sociologia e da Ciência Política, sobre o político Guerreiro Ramos. Essa hipótese consiste no fato de que o sociólogo acreditava numa revolução social e política, mas era cético quanto aos seus atores: os partidos (PCB e PTB), por um lado; por outro, não verificava consistência na sociedade civil organizada, expressa pelos intelectuais reunidos no ISEB, por exemplo, sindicatos e movimentos urbanos e rurais. Esse paradoxo persegue as posições críticas de Guerreiro Ramos até o momento em que foi cassado pelo golpe militar, em abril de 1964. Outro propósito subsidiário de nossa hipótese é verificar também a contribuição do sociólogo e político para a Sociologia e a Ciência Política brasileira, considerando os projetos em disputa sobre o desenvolvimento em curso no país nos anos de 1950 e 1960, na esteira do golpe militar de 1964.

Palavras-chave: Sociologia. Ciência Política. Guerreiro Ramos. Desenvolvimentismo. Pensamento Brasileiro e Golpe Militar de 1964.

\section{Abstract}

In this article, we will pursue the hypothesis, in some dimensions already explored in the field of Sociology and Political Science, about the political Guerreiro Ramos. It consists in the fact that the sociologist believed in a social and political revolution, but was skeptical of its actors: political parties (PCB and PTB) on the one hand; and on the other, he didn't felt consistency in organized civil society, expressed by intellectuals gathered in the ISEB, for example, trade unions and urban and rural movements. This paradox permeates the criticism from Guerreiro Ramos positions until the time that his term was revoked by the military coup in April 1964. Another subsidiary purpose of our hypothesis is to verify the contribution of the sociologist and politician to Sociology and Brazilian Political Science, considering the projects in dispute on the development underway in the country in the 50 s and 60s of the twentieth century in the wake of the 1964 military coup.

Keywords: Sociology. Political Science. Guerreiro Ramos. Developmentalism. Brazilian Social Thought and 1964 Military Coup. 


\section{Contexto}

Brasil das décadas de 1950 e 1960 do século XX viveu um de seus momentos históricos mais conturbados e efervescentes no plano político, econômico e social. Por um lado, a esperança de tornar-se uma potência em desenvolvimento, portanto, industrializada, ancorada nas concepções desenvolvimentistas no plano da economia e da política, laureados pelo pensamento nacional-popular². Por outro, a "vocação" autoritária do pensamento político brasileiro 3 habitava as ideologias desenvolvimentistas e liberais sobre as visões da realidade nacional. A primeira admite a participação popular e fomenta o debate público. A segunda, pressionada justamente pelas manifestações populares, as insurgências políticas internas e expansão internacional dos movimentos comunistas, aposta no golpe militar.

No plano político, o suicídio do presidente Getúlio Vargas, no dia 24 de agosto de 1954, e as eleições presidenciais de 1955 estabelecem a segunda cena do confronto udenista de Carlos Lacerda com a aliança PSD e PTB, em que Juscelino Kubitschek, candidato a presidente da República, e João Goulart, a vice, saíram vitoriosos, embora Juscelino tenha obtido uma margem apertada, 36\% dos votos válidos, contra 30\% de Juarez Távora, general do Exército. As eleições para vice-presidente eram independentes e João Goulart arrasou seus adversários, superando a votação de Juscelino: 3.591 .409 contra 3.077.41 1 eleitores (Schwarcz; Starling, 2015), que o legitimou a vice na candidatura de Jânio Quadros, em 1960.

Nos âmbitos econômico e social, o Plano de Metas bem sucedido impulsionou o crescimento econômico, fortaleceu a indústria e o consumo, alavancou a infraestrutura e colocou no horizonte a inauguração 
da nova capital, Brasília. Era ainda beneficiado com as políticas de proteção social da era getulista.

O sociólogo, político e deputado federal, meses antes do golpe militar, é ator privilegiado desses acontecimentos históricos. Fez parte do Instituto Superior de Estudos Brasileiros (ISEB), órgão ligado à Casa Civil da Presidência da República, como diretor do Departamento de Sociologia, desde 1955, quando o instituto foi criado. Em 1958, afastou-se por divergências com Álvaro Vieira Pinto e Hélio Jaguaribe. A partir de então, ingressou na política partidária. Em 1959, foi eleito para o Diretório Nacional do Partido Trabalhista Brasileiro (PTB) e, em 1962, candidatou-se a deputado federal pelo partido.

\section{A Sociologia e a Ciência Política em Guerreiro Ramos}

A sociologia e a política ocuparam a vida e a obra de Guerreiro Ramos. Na Sociologia, a questão nacional, os paradigmas sobre o desenvolvimento brasileiro e seus limites, o "problema do negro", como assim denominou, a teoria das organizações e suas estruturas, são matriciais no seu pensamento sociológico. Na Ciência Política, seu campo de interesse tem foco privilegiado nas relações de poder, onde explora as relações partidárias, governos e sociedade. Sua visão critica em particular, no texto sobre os processos da revolução brasileira, seja como mito ou verdade, nos anos 1960, é singular nos estudos da ciência política brasileira.

Nesta primeira parte do artigo, será apresentada uma breve síntese do pensamento de Guerreiro Ramos, no campo da Sociologia e da Ciência Política. Vamos nos valer em grande medida do artigo produzido para a Revista Esboço (Revista Esboço, n. 15, 2006), em que está concentrada a apresentação de Guerreiro Ramos, a partir de uma série de depoimentos de cientistas políticos, sociólogos, antropólogos, economistas que conviveram, divergiram, disputaram sua ideias e o reconheceram como um dos mais importantes pensadores e combatentes nos horizontes da sociologia e das ciências políticas no Brasil. Do mesmo modo, continuaremos explorando suas teorias e práticas sobre o "Mito da revolução brasileira" (Guerreiro Ramos, 1963), concebida por ele como "cena histórica" do "povo brasileiro", não como 
processo histórico descontínuo, o qual criticava. Sua originalidade reside no método ${ }^{4}$ pelo qual desenvolveu suas teorias, sobretudo como interpretou a realidade política, social, econômica e cultural brasileira.

Guerreiro Ramos é de enorme atualidade. Sua notoriedade pública e reconhecimento acadêmico nas ciências sociais no Brasil são expressos nos depoimentos de cientistas sociais, escritores e intelectuais com reconhecida trajetória na academia. Para o sociólogo Wanderley Guilherme dos Santos,

Alberto Guerreiro Ramos pertence a um grupo sociológico especial - o daqueles intelectuais destinados ao martírio. Intelectuais que se distribuem pela literatura, música, artes plásticas, ciências sociais e têm em comum a total, completa e absoluta falta de respeito pelas convenções que asseguram glória, fama e tédio. São, por isso, condenados ao ostracismo, à quarentena tácita e, às vezes, no limite, a tormentos pessoais. Ainda assim, fossem de fato rufióes das letras, charlatões dos palcos, exibicionistas das esculturas, tintas e cores, bufos da reflexão social, ainda assim, e o amanhã, depois deles, transforma-se em perene invenção. Fim da rotina. Guerreiro Ramos, recado aos distraídos, destroçou a "sociologia sorriso da sociedade", desmoralizou a sua linguagem, exumou sua natureza gélida e, feito maior, revelou que a sociologia oficial era menos um retrato ou reflexão sobre a sociedade do que ingrediente teorizante indispensável para que a sociedade continuasse a mesma. Por exemplo, uma sociedade constituída majoritariamente por negros, discriminados e oprimidos, necessitava, para permanecer idêntica a si própria, de um credo científico que afirmasse justamente o oposto. Essa é a "Sociologia sorriso da sociedade" (Guerreiro Ramos, 1995, contracapa)

Abdias do Nascimento, amigo e companheiro de Guerreiro Ramos (militaram juntos no Teatro Experimental do Negro, na década de 1940), seguramente personagem e militante das mais importantes do movimento negro contemporâneo, ao comentar uma de suas obras afirmou que

[...] a redução sociológica é referência básica para todos os que pensam com autonomia a fundação de uma sociologia brasileira com identidade própria. Esse é o caminho da 
nossa cultura, descolonizada, capaz de se afirmar e se diferenciar no nível da universalidade. (Guerreiro Ramos, 1996, contracapa)

Para o economista Celso Furtado, a mesma obra, A Redução Sociológica,

[...] sobressai como uma das mais inovadoras das ciências sociais brasileiras, marcadas então por contribuições repetitivas e de escassa originalidade, o que faz ainda mais singular, abrindo horizontes sobre os nossos problemas sociais. (Guerreiro Ramos, 1996, contracapa)

Clóvis Brigagão, cientista político e escritor, aluno do professor Guerreiro Ramos na Escola Brasileira de Administração Pública da Fundação Getúlio Vargas (FGV), quando se tornaram amigos, profundo conhecedor da obra de Guerreiro, escreveu no prefácio à terceira edição da A Redução Sociológica, em 1996:

Passadas quase quatro décadas desde que Guerreiro Ramos publicou, em 1958, a primeira edição da Redução Sociológica, sua veemência se faz ouvir. Ali, o mestre Guerreiro sustentava teses com alta dose de coragem intelectual, inspiradas no método crítico sobre hábitos, racionalizações e usurpações teóricas que habitavam (e ainda habitam) o pensar e o fazer sobre os destinos de nossa sociedade. É marca inconfundível desse clássico da sociologia o rasgar das ilusões que embotavam os fatos sociais, suas considerações e pressupostos teóricos sobre o desenvolvimento brasileiro. (Guerreiro Ramos, 1996, Prefácio)

Em A Redução Sociológica, Guerreiro tratava, com sucesso, de dois embates: a liquidação da mentalidade colonial, bem como suas decorrências no plano das ideias e da política, e a exposição, com toda a sua inequívoca radicalidade e clarividência, das razões sobre a nova consciência crítica da realidade, por meio do exame metódico e filosófico que ele esgrimia sem parcimônias e gratuidades. Brigagão, neste mesmo prefácio, faz a pergunta acerca da atualidade do pensamento e da obra de Guerreiro Ramos: "Seria a Redução ainda atual, atuante e explicativa sobre o desenvolvimento brasileiro?", e afirma, “[...] 
continua sendo instrumental válido e insuperável da postura crítica e criativa das mais originais já produzidas em nosso país." (Guerreiro Ramos, 1995, p. 13).

Eduardo Portela e Darcy Ribeiro também comentaram a obra de Guerreiro Ramos. Para Eduardo Portela, Guerreiro Ramos era um cientista social que pensava. Pensava para além dos limites de sua possível especialização. Era igualmente o escritor que se distinguiu pelo modo singular de levar adiante a trama da linguagem. Daí a elegância, a transparência, a vida que conseguiu infundir a seus textos. Guerreiro Ramos tinha como horizonte o saber universal, e como solo, como preocupação de todos os minutos, a cena histórica de sua gente -vezes esparsa, vezes constante. A Redução Sociológica vem a ser isto: o nosso diálogo áspero e criativo entre conhecimento e interesse. Foi seu autor o ator instigante, o protagonista inconfundível da nossa contemporaneidade intelectual.

Para Darcy Ribeiro, antropólogo e escritor que registrou o seu depoimento no livro Introdução Crítica à Sociologia Brasileira, Guerreiro foi um dos melhores nas ciências sociais:

Fui amigo e até compadre de Guerreiro Ramos. Depois brigamos. Ele queria liberar todo pesquisador social de países atrasados como o nosso das prescrições metodológicas formais. Nós todos reagimos num Congresso de 52, no Rio, a que ele respondeu com a sua excelente Cartilha. Eu era, então, um etnólogo bisonho, metido com os índios, querendo estudá-los como fósseis vivos. Florestan queria ser Merton. Guerreiro tinha toda a razão de propor uma ciência social nossa, eficaz e socialmente responsável. Exacerbou, é claro, como todo pioneiro. Mas era, sem dúvida, o melhor de nós. (Guerreiro Ramos, 1995, contracapa)

Os depoimentos acima registrados elucidam a importância de Guerreiro Ramos nas ciências sociais e nas humanidades, sua contribuição inegável para a construção de um projeto de nação tão sonhado e almejado nos anos 1930 até o início da década de 1960 para o Brasil e os brasileiros.

Guerreiro Ramos pensava o projeto de desenvolvimento como instrumento de inclusão social, onde negros e todos os excluídos não 
fossem objeto de uso nos estudos e pesquisas nas ciências sociais, ou mão de obra barata nos processos de produção, mas sim sujeitos de direitos no desenvolvimento das políticas públicas. Infelizmente, essa perspectiva não foi a predominante. O Brasil tornou-se uma das nações com a maior concentração de renda do mundo em longo do século $\mathrm{XX}$, com pequenas transformações substantivas e, como consequência, carregamos os indicadores mais brutais de desigualdades sociais neste início do século XXI, com a predominância desse estado de injustiça na população negra e nas mulheres de modo geral, uma combinação de exclusão e dominação focados no tripé: gênero, raça e classe social.

\section{A Régua e o Compasso de Guerreiro: Bahia e Rio de Janeiro}

Alberto Guerreiro Ramos nasceu na cidade de Santo Amaro da Purificação, na Bahia, em 1915, e morreu em Los Angeles, na Califórnia (Estados Unidos), em 1982, aos 67 anos. As informações sobre a sua chegada à capital baiana ainda são uma lacuna na biografia do sociólogo. Sua participação no meio acadêmico e intelectual, no entanto, ganhou destaque quando Guerreiro Ramos ainda era muito jovem. Aos 18 anos, nomeado assistente na Secretaria da Educação da Bahia, já escrevia frequentemente artigos e críticas literárias para publicações de Salvador, como O Imparcial, jornal bastante influenciado pelas ideias europeias, especialmente as veiculadas pelas revistas francesas L'Esprit e L'Ordre Nouveau.

Foi nesta época também que Guerreiro Ramos escreveu o livro de poemas O drama de ser dois (1937). Dedicada ao teólogo russo Nicolau Berdiaff, a obra é, para Guerreiro, essencial para encontrar um sentido para a sua existência, disse, em entrevista concedida a Alzira Alves de Abreu e Lucia Lippi Oliveira, nove meses antes de morrer.

Nesse poema eu me descrevia como uma espécie de pessoa entre dois mundos que eu não sabia definir. E ainda hoje acho que esse é um traço fundamental do meu perfil: eu não pertenço a nada. Não pertenço a instituições, não tenho fidelidade a coisas sociais; tudo o que é social, para mim, é instrumento. Eu não sou de nada, estou sempre 
à procura de alguma coisa que não é materializada em instituição, em linha de conduta. (Oliveira, 1995, p. 134)

Por sua capacidade, Guerreiro Ramos foi escolhido para integrar o grupo de fundadores da Faculdade de Filosofia da Bahia. Também militou sob a inspiração da linha católica de Jacques Maritain, fundou o Centro de Cultura Católica e publicou o livro de ensaios Introdução à Cultura (1939), pela Cruzada da Boa Imprensa.

Ao lado de Afrânio Coutinho, com quem mantinha amizade, publicou a revista Norte. Mas a fama que ele alcançou na capital baiana foi apenas um incentivo para buscar novos horizontes de amadurecimento intelectual. Aos 24 anos, foi agraciado com uma bolsa de estudos do governo do estado da Bahia para estudar Ciências Sociais na Faculdade Nacional de Filosofia do Rio de Janeiro, então Universidade do Brasil. Ele terminou o curso em 1942 e, um ano depois, obteve o diploma em Direito pela Faculdade de Direito do Rio de Janeiro.

O efervescente clima político e intelectual na então capital federal influenciou, em muito, a produção de Guerreiro Ramos. Colaborou com a revista Cultura Política com seus artigos de análise literária; traduziu os poemas do alemão Rainer Maria Rilke; influenciado por Murilo Mendes, contribuiu com a revista cultural Tentativa, de Minas Gerais; leu Tasso da Silveira, Adalgisa Nery, Platão, Hölderlin, Novallis, Gerard de Nerval, Émile Durkheim, Karl Mannheim, Karl Marx e Max Weber, este último, segundo Guerreiro Ramos, “[...] a influência mais poderosa desde os anos 40 até hoje (década de 80), em termos da minha profissão de homem de ciência social [...]" (Oliveira, 1995, p. 144), conforme Alzira Alves de Abreu e Lucia Lippi Oliveira registraram.

Apesar da formação e do reconhecimento acadêmico, Guerreiro Ramos passou um ano desempregado, após finalizar os cursos universitários. Depois deste período de crise, considerado importante pela dedicação e bondade que os amigos dispensaram, ele foi convidado a ingressar no serviço público. Um serviço burocrático para um intelectual de seu nível, mas uma chance também para continuar produzindo, fazer circular suas ideias e entender a realidade política do Brasil. Nesse período, colabora para a Revista do Serviço Público, escrevendo artigos sobre Max Weber. 
Em 1952, ministrou a primeira aula na Escola Brasileira de Administração Pública (EBAP) e, mais tarde, tornou-se professor de Sociologia da Escola de Administração Pública da Fundação Getúlio Vargas (FGV). Guerreiro Ramos trabalhou diretamente no governo Vargas, especialmente na assessoria econômica, fazendo a elaboração de projetos. Nesse período, ele fundou, ao lado de outros intelectuais, o Grupo de Itatiaia, com o objetivo de compreender os problemas brasileiros e elaborar relatórios sobre economia e política do país.

O livro Introdução Crítica à Sociologia Brasileira, lançado em 1957, é, para Guerreiro Ramos, o primeiro trabalho e para ele o mais lúcido, onde aborda criticamente a dependência metodológica da sociologia brasileira, seu descolamento da realidade nacional, que denominou de "sociologia enlatada", "sociologia consular". No mesmo texto, aborda criticamente a questão racial no país, no texto "O Problema do Negro na Sociologia Brasileira" onde contextualiza naquele período, as relações raciais no Brasil. O sociólogo identificava três grandes correntes no desenvolvimento dos estudos afro-brasileiros (Oliveira, 1995, p. 163): a primeira, defendida por Sylvio Romero (1851-1914), Euclides da Cunha (1866-1909), Alberto Torres (186519170), e Oliveira Viana (1883-1951), que se caracteriza pela atitude "crítico-assimilativa", concluía que,

[...] apesar das diferentes orientações teóricas desses autores, todos eles estavam interessados antes na formulação de uma teoria do tipo étnico brasileiro do que extremar as características peculiares de cada um dos contingentes formadores da nação. No que diz respeito ao elemento negro, embora ressaltem a sua importância, contribuíram para arrefecer qualquer tendência para ser ele considerado do ângulo do exótico, ou como algo estranho na comunidade. (Oliveira, 1995, p. 168)

Identificava uma segunda corrente, que denominou de "monográfica", cujos expoentes eram Nina Rodrigues (1862-1906), Arthur Ramos e Gilberto Freyre. Afirmava que o negro nesta corrente tornouse "assunto", tema de especialistas,

[...] cujos estudos pormenorizados promoveram, entre nós, movimento de atenção de uma parcela de cidadãos 
para os chamados afro-brasileiros. Interessava-lhes o passado da gente de cor ou as sobrevivências daquele no presente. (Oliveira, 1995, p. 169)

A terceira corrente, que chamou de Nova Fase, iniciava-se em 1944, com o Teatro Experimental do Negro (TEN), liderado por Abdias do Nascimento: “É, no Brasil, a manifestação mais consciente e espetacular da nova fase, caracterizada pelo fato de que, no presente, o negro se recusa a servir de mero tema de dissertações antropológicas e passa a agir no sentido de desmascarar os preconceitos de cor" (Guerreiro Ramos, 1993, p. 205). Guerreiro Ramos não desenvolveu estudos e pesquisas sistemáticos sobre as relações raciais no Brasil, mas compreendia os negros como "povo" e, portanto, estratégico para o desenvolvimento nacional.

A vivência como intelectual negro e militante, como foi no Teatro Experimental do Negro, rendeu-lhe a seguinte inscrição no Conselho de Segurança Nacional: "Alberto Guerreiro Ramos, mulato, metido a sociólogo". Na entrevista a Alzira Alves de Abreu e Lucia Lippi Oliveira, Guerreiro Ramos disse que nunca viveu racismo maior do que no Brasil, nem mesmo nos Estados Unidos, onde estava radicado à época. Na Califórnia, em entrevista concedida no ano de 1981, afirmou que "[...] o Brasil é o país mais racista do mundo" (Oliveira, 1995, p. 174).

Outro momento importante como intelectual e político. Em 1961, foi convidado pelo Partido Comunista Brasileiro e pela Academia de Ciências de Moscou a conhecer a então União Soviética. No retorno ao Brasil, teceu longas críticas aos comunistas, pela visão estreita que eles tinham das questões sociais e da política internacional.

Para ele, a vida fora do país aguçou a sua percepção para entender o Brasil. A história do Brasil é muito mal contada, é preciso reescrevê-la. A base da narração da história brasileira está na capitulação de quem a escreve, que é o não reconhecimento de que a existência do Brasil transcorreu até agora dentro do ciclo da decadência, comentou o sociólogo, que também registrou passagem pela Comissão Econômica para a América Latina e Caribe (Cepal).

Guerreiro Ramos escreveu dezenas de livros e artigos. Entre eles, o processo da sociologia no Brasil - Esquema de uma história das idéias (1953), 
A Redução sociológica (1958) e O problema nacional do Brasil (1960). Em A crise do poder no Brasil (1961), o autor mostra como o processo de industrialização tirou do mapa algumas das principais oligarquias brasileiras. Também publicou A Sociologia da Mortalidade Infantil (1955), em espanhol, no México. Na época de sua morte, lecionava na Escola de Administração Pública da Universidade do Sul da Califórnia.

\section{A Crítica e o Método}

A sociologia a ciência política e, em grande medida a filosofia, são áreas do conhecimento que orientam a vasta obra do cientista social Alberto Guerreiro Ramos, sua sociologia crítica, marcada desde a primeira edição da Cartilha Brasileira de Aprendiz de Sociólogo ( $1^{\text {a }}$ edição em 1954, depois reeditada como Introdução crítica à sociologia brasileira, em 1957) até a publicação do texto A Nova Ciência das Organizações, sua última obra, no conjunto indicam o método e a inquietude crítica frente aos desafios das ciências e da política que produziu. Repousa neste espectro sua validade quando testada na atualidade, seus conceitos sociológicos desenvolvidos.

Para Clóvis Brigagão, pela primeira vez a sociologia no Brasil, inaugurada por Guerreiro Ramos, é colocada em seu devido lugar, quer pela sua instrumentalidade teórica, quer pela sua inserção no contexto da sociedade brasileira. Para Brigagão, sua atualidade deve-se ao fato de que os atributos científicos do autor, sobre a sociologia e a sociedade, continuam como arcabouços que influenciam comportamentos, atitudes e hábitos até os nossos dias (Guerreiro Ramos, 1995).

Para a socióloga Lucia Lippi Oliveira, "[...] a maioria dos cientistas sociais do país reconhece a importância do nome de Guerreiro Ramos. Saudado como um dos pais da sociologia brasileira contemporânea $[\ldots]$, abriu as portas para uma ciência social que, apesar de aceitar a objetividade e a universalidade, recusa a neutralidade". Para Guerreiro Ramos, "A essência de toda a sociologia autêntica é, direta ou indiretamente, um propósito salvador e de reconstrução nacional". Guerreiro Ramos foi um pensador que encantou e assustou uma academia branca, eurocêntrica e elitista, pouco disposta a enfrentar os 
"problemas nacionais" (Guerreiro Ramos, 1958).

As ciências sociais viviam um momento de forte processo de institucionalização iniciado nos anos 30, com a criação da Escola Livre de Sociologia e Política de São Paulo, em 1933, e pela fundação da Universidade de São Paulo (USP). O clima, intelectual e político, ainda abrigava as polêmicas das recentes Abolição da Escravatura, em 1888, e Proclamação da República, em 1889 (menos de 50 anos separavam estes momentos). Juntava-se a isso a longa tradição das faculdades de Direito e Medicina, como a de Direito inaugurada em Olinda (PE), no ano de 1828. Do mesmo modo, em Salvador (BA), duas escolas influentes, com nomes do porte de Gilberto Freyre, em Pernambuco, e Nina Rodrigues, na Bahia.

Estavam na ordem do dia, no mundo das relações raciais, os debates em torno da teoria do branqueamento e da democracia racial. A primeira preconizava o futuro da sociedade brasileira não como negra ou mestiça, fortemente marcada pelas ascendências indígenas e negras, mas sim predominantemente europeia, branca se não na cor, pelo menos na alma - parafraseando Silvio Romero (1888-1949), que afirmava que somos um país mestiço: "Somos mestiços se não no sangue ao menos na alma" dizia o crítico literário e respeitado intelectual, ao comentar a composição étnica da população brasileira (Schwartz, 1993).

A perspectiva da tese do branqueamento foi apresentada como "ciência" no I Congresso Internacional das Raças, realizado em Londres, em 1911. Na ocasião, o representante do governo brasileiro, João Batista Lacerda, então diretor do Museu Nacional do Rio de Janeiro, afirmou sem nenhuma dúvida impressionista que “[...] o Brasil mestiço de hoje tem no branqueamento em um século sua perspectiva, saída e solução" (Schwartz, 1993).

A segunda, a democracia racial, ancorada no binômio Gilberto Freyre e sua principal obra, Casa Grande e Senzala, lançada em 1933, tornou-se referência absoluta no pensamento sociocultural e político dos anos de 1930 aos anos de 1950. Casa Grande e Senzala foi aclamado como uma ruptura nos estudos históricos e sociais tanto pelo tema - a formação de uma sociedade agrária, escravocrata e híbrida - quanto 
pelas ideias, como a valorização do escravo negro e da cultura afro-brasileira. Da degeneração étnica decantada por tantos, o Brasil se converteu em paraíso tropical e mestiço, em que se daria a confraternização de raças e culturas oriundas da Europa com os imigrantes, África com os negros e a América. A ideia de uma história em que os conflitos se harmonizam passou a fazer parte do senso comum brasileiro e da cultura política do país, tendo sido veiculada pelos sucessivos governos a partir dos anos de 1940. O mito da democracia racial se tornou um obstáculo para o enfrentamento das questões étnico-raciais e sociais, na medida em que os negros, os povos indígenas e as mulheres, sobretudo, ficaram submetidos e restritos ao conceito de classe social. Com isso não foram considerados sujeitos ativos nas transformações em curso, isolados como mera mão de obra no processo do desenvolvimento nacional.

O Brasil das últimas três décadas do século XIX até os anos de 1960, viveu, sem dúvida, os seus maiores desafios e as suas mais profundas contradições culturais, econômicas, políticas e sociais. As relações fortemente racializadas, as crises econômicas internas (transição da mão de obra do trabalho escravo, crise da economia cafeeira, deslocamento do centro dinâmico, processos de urbanização etc.) e externas (impacto dos processos da Primeira Revolução Industrial, as consequências da Primeira Guerra Mundial com um novo realinhamento e polarização dos blocos econômicos), forçam os países em desenvolvimento a enormes dificuldades.

É nesse ambiente que o Brasil vai sendo construído como EstadoNação, no final do século XIX e início do século XX, e quando o projeto de desenvolvimento econômico, com seus contornos e perspectivas nas áreas da educação, do trabalho, saúde, desenvolvimento industrial e urbanização, vai sendo processado, na esteira das concepções nacionalistas, desenvolvimentistas e populistas.

Guerreiro Ramos está no centro deste momento histórico do Brasil, sendo um dos principais intelectuais integrante do ISEB, junto com Nelson Werneck Sodré, Álvaro Vieira Pinto, Hélio Jaguaribe, Ignácio M. Rangel e outros. Suas principais obras datam deste período. Ele próprio a definia como construção de uma atitude crítica da ciência e 
da cultura importadas, como forma de habilitar o sujeito a resistir à massificação de sua conduta e às pressões sociais organizadas.

No livro Introdução Crítica à Sociologia Brasileira, de 1957, Guerreiro Ramos constrói a "arvore genealógica" do pensamento mais original da sociologia brasileira, tece o fio condutor das raízes do pensamento sociológico nacional. Alguns textos merecem destaque na Introdução Crítica: Crítica da Sociologia Brasileira, Cartilha Brasileira do Aprendiz de Sociólogo e Documento de uma Sociologia Militante. Importante neste último texto a construção teórica que faz sobre a "patologia social do branco brasileiro", debate que reaparece no final do século XX, nas principais universidades brasileiras, nas áreas do conhecimento da psicologia social.

Outra importante produção do sociólogo é o livro Redução Sociológica, de 1958, para muitos estudiosos a principal obra de Guerreiro Ramos, considerada a mais original contribuição do pensador para a formulação de um desenvolvimento nacional, despertando novas atitudes e métodos políticos e administrativos no panorama brasileiro. A obra tem como um dos propósitos combater as tentativas de tornar a sociologia uma ciência elitista, apontando para a necessidade de democratizar o saber sociológico como instrumento substancial para as transformações sociais. Na nota introdutória à segunda edição, o autor afirma que a redução sociológica é um método destinado a habilitar o estudioso a praticar as transposições de conhecimentos e de experiências de uma perspectiva para outra. O que inspira é a consciência sistemática de que existe uma consciência brasileira. Toda cultura nacional é uma particularidade. Eis porque a redução sociológica é, apenas, modalidade restrita de atitude geral que deve ser assumida por qualquer cultura em processo de fundação (Guerreiro Ramos, 1993).

Destaca-se também nesta obra o que Guerreiro Ramos chamou de "Consciência Crítica da Realidade Nacional". Analisava-a como um dado objetivo da realidade social brasileira. Para ele, não se tratava de anelo de uns poucos, preocupados em modelar um caráter nacional mediante processos, por assim dizer, paretianos, ou seja, pela manipulação de resíduos emocionais populares. O fenômeno tem suporte na massa. Um estado de espírito generalizado não surge arbitrariamente. 
Reflete sempre condições objetivas que variam de coletividade para coletividade.

Outro tema que o sociólogo perseguiu de maneira obstinada com lucidez e precisão foi o desenvolvimento, que chamou no texto de "Critérios de Avalição do Desenvolvimento". A preocupação do sociólogo neste campo de conhecimento em buscar construir instrumental de análise para compreender e impulsionar o projeto de desenvolvimento, a partir da realidade nacional, portanto, combater a mentalidade colonial, os eurocentrismos como fonte única de reflexão e conhecimento, era um dos apetites filosóficos e sociológicos de Guerreiro Ramos. Nesse universo de investigação e ação política, teve a oportunidade de, em 1961, como delegado representando o Brasil na XVI Assembleia Geral das Nações Unidas, analisar e apresentar o Relatório do Conselho de Desenvolvimento Econômico e Social das Nações Unidas sobre a Situação Social do Mundo. Fez na ocasião um pronunciamento contundente, principalmente porque o documento tratava superficialmente "fatores políticos ligados à abolição do regime colonial", e chamava a atenção do Conselho de Desenvolvimento Econômico da ONU para a necessidade de maior equilíbrio entre os países desenvolvidos e os que estavam em processo de desenvolvimento e descolonização nos continentes africano, asiático e americano.

No decorrer dos anos de 1960, Guerreiro Ramos produziu três obras importantes no campo da ciência política e da sociologia política. São textos que marcaram o debate público sobre os destinos do país, mas também estavam marcados pela conjuntura política dos anos de 1960 no Brasil. Na primeira obra, o Problema nacional do Brasil, de 1960, o autor produziu uma reflexão inovadora sobre vários temas da realidade nacional, abrangendo ideologia e segurança nacional; relações sociais e poder, os grandes temas que estavam diretamente interligados com a vida da população e os destinos do país.

A segunda importante obra, A crise do poder no Brasil, de 1961, é considerada um clássico na área de análise da política e dos elementos que formam as contradições, as conjunturas e as lutas do poder social e de Estado. É uma das mais importantes contribuições para compreendermos as determinações da ordem política conservadora e 
a ordem reformista e popular no Brasil. Neste livro, o sociólogo analisa com precisão o clima político que ia se formando na antessala do golpe de 1964.

Guerreiro Ramos, como parlamentar (deputado federal representando o estado do Rio de Janeiro) no período de agosto de 1963 a abril de 1964, fez cerca de 30 pronunciamentos sobre temas políticos nacionais e internacionais, sendo o seu último discurso no dia 16 de abril, quando perdeu seus direitos políticos e foi cassado pelo Governo Militar. Parece ironia, mas a sua obra mais polêmica no campo da ciência política, Mito e Verdade da Revolução Brasileira, publicado em julho de 1963, aponta os graves "erros" que estariam sendo cometidos por setores e organizações sociais, sindicais e partidárias que queriam, justamente, a garantia da institucionalidade, da legalidade, da democracia e das transformações necessárias para o desenvolvimento do Brasil.

Esta terceira obra, Mito e Verdade da Revolução Brasileira, é considerada por muitos cientistas sociais, historiadores e intelectuais (Brigagão, Ianni, Cardoso, Ramos, Campos), como a mais inquietante produzida por Guerreiro Ramos. Para Clovis Brigagão,

O mais fascinante livro de Guerreiro Ramos, polêmico, visionário, escrito no contexto do pré-Golpe Militar: e uma contundente e arrasadora crítica teórica e política sobre as forças e grupos intelectuais e de políticos da esquerda brasileira, especialmente sobre o Partido Comunista Brasileiro. Parafraseando a famosa peça teatral de Eugène Ionesco, O Rinoceronte, Guerreiro Ramos passa a limpo (em especial no cap. VII - Revolução Brasileira ou Jornada de Otários), com fina ironia e clareza de análise, as tendências e os sintomas do processo político às portas do golpe militar de 31 de março de 1964.

Nesta obra, Guerreiro Ramos volta a questões teóricas e de análise, centrais, que se apresentavam na Redução Sociológica (1958) e na Cartilha Brasileira de Aprendiz de Sociólogo (1954). Como o conceito de "redução sociológica", compreendido como método de assimilação crítica da produção sociológica estrangeira; como atitude parentética, isto é, transcender no limite do possível, os condicionamentos cir- 
cunstanciais que conspiram contra a sua expressão livre e autônoma; a sociologia como ciência do fazer.

Ciência e política, a sociologia da ação, militante, foram combinações no campo da teoria e da prática, que fizeram de Guerreiro Ramos um homem público, combatente a favor das grandes causas nacionais, mas, sobretudo, um cientista social, que acreditava numa perspectiva de revolução brasileira.

\section{O Sociólogo e o Golpe de 1964}

No prefácio do livro Mito e Verdade da Revolução Brasileira, Guerreiro Ramos escreveu o que, em grande medida, sintetiza toda a sua reflexão e crítica ao processo em curso que se teve da perspectiva da "necessária" revolução brasileira, a partir da década de 1960. Debatida e construída por seus protagonistas, a menos de um ano do golpe militar, afirmava ele que

[...] o movimento emancipador do Brasil está ameaçado de grave desnaturação por duas debilidades que o acometem; uma, de ordem cultural; outra, de natureza organizacional. Vivem largamente os que pretendem liderá-lo de teorias de empréstimo e de ficções literárias e conceptuais, que não traduzem, com o mínimo de exatidão requerida, as tendências concretas do processo brasileiro, em sua presente etapa. (Guerreiro Ramos, 1963, p. 9)

No Capítulo 1, no qual escreve o que chamou de Pequeno Tratado Brasileiro da Revolução, desenvolve sua compreensão sociológica e política da revolução brasileira:

Revolução é categoria viva da história contemporânea do Brasil. Por isso, encontra-se o sociólogo brasileiro numa situação privilegiada, que não deve malbaratar, mas aproveitar, em sua riqueza conceptual, na promoção do progresso científico. Assim sendo, o estudo do processo revolucionário envolve mais do que um teste de preparo profissional ou de competência acadêmica. Envolve, sobretudo, um teste de sensibilidade humanística. (Guerreiro Ramos, 1963, p. 17) 
Para Guerreiro Ramos, era necessário compreender e desenvolver o conceito da revolução em processo no país. Reconhecia em Blanqui, Marx e Lênin, referências importantes para o que chamou de "enfocamento da tarefa revolucionaria", mas acreditava que era da maior urgência, considerar com profundidade os elementos objetivos e subjetivos das classes ou coalizão de classes nos processos de mudanças e de luta pelo poder. Considerava, no conceito de revolução, alguns princípios fundamentais: o da práxis, o de limites, o da classe social e o de totalidade (Guerreiro Ramos, 1963).

O princípio da práxis, para Guerreiro, é a combinação dos elementos objetivos e subjetivos, que não são questões abstratas no processo revolucionário: "A prática é criação simultânea do homem e de seu mundo exterior. O homem se faz a si mesmo na medida e enquanto participa da elaboração da sua circunstância externa, que, assim, equivale à materialização do seu trabalho" (Guerreiro Ramos, 1963, p. 31) .

O princípio dos limites são circunstâncias objetivas que se impõem e que exigem de imediato apurado esforço de análise e, neste momento contraditório, portanto dialético, é que a teoria revolucionária e sua compreensão passam a ter validade real. Guerreiro Ramos explica estas variáveis da seguinte forma: uma posição que, em dado momento da luta de classes, figura-se viável ou oportuna, em outro, pode tornar-se o contrário. Não há regras fixas, receitas uniformes nesse domínio. Em toda situação revolucionaria há um número limitado de possibilidades. A revolução é uma transformação consciente da sociedade e, portanto, em certo sentido, uma questão de consciência. Mas de uma consciência portadora de qualificações específicas que a distinguem da consciência ingênua, da consciência vulgar, da falsa consciência - a teoria objetiva da consciência de classe e a teoria de sua possibilidade objetiva. Os homens fazem a sua própria história, mas não a fazem como querem, não a fazem sob as circunstâncias de sua escolha, e sim sob aquelas com que defrontam diretamente, ligadas e transmitidas pelo passado (Guerreiro Ramos, 1963, p. 33). Guerreiro Ramos ancorava a teoria do princípio dos limites em clássicos da literatura revolucionária como Georg Lukács (História e Consciência de Classe), Karl Marx (O 18 Brumário de Luis Bonaparte), e Lênin (Estado e Re- 
volução), principalmente. Mas assentava a sua análise, e concepções, nos fatos históricos institucionais e populares da sociedade brasileira.

Dois exemplos se destacam: a análise que faz do golpe de 1937, e o Plano Cohen, que serviu para criar clima de ameaça comunista com a qual se justificou o golpe de 10 de novembro de 1937; do mesmo modo, a leitura singular que fez a respeito da renúncia do presidente Jânio Quadros, em agosto de 1961, seguida da resistência capitaneada pelo governador do Rio Grande do Sul, Leonel Brizola, para garantir a posse do vice-presidente João Goulart.

O princípio da classe social, conceito para ele carregado de controvérsias, mas entendido como um conceito chave e definidor no processo revolucionário. Anunciava com este princípio o sujeito coletivo destinatário do processo revolucionário: toda revolução tem destinatários - uma verdadeira revolução só se realiza quando o seu destinatário é uma classe ou uma coalizão de classes representativa de avanço no nível das forças produtivas - para o quadro revolucionário estar situado concretamente na luta de classes equivale a contar com uma organização mediante a qual garante permanente contato com as camadas sociais que representa. Sem essa espécie de organização, jamais se consegue promover transformação de envergadura, no domínio econômico, político e social, e a própria estabilidade de poder (Guerreiro Ramos, 1963, p. 37).

O princípio da totalidade - totalidade compreendida aqui como o conjunto de fatores endógenos e exógenos que envolve um processo revolucionário, como conceito autoabrangente - toma o ser como totalidade concreta e também plenamente intensiva. Para o sociólogo Guerreiro Ramos (1963, p. 37),

O princípio da totalidade não concerne apenas aos assuntos de tática e estratégia. É princípio metódico, de análise científica da realidade social. A revolução é movimento consciente que visa efetivar uma possibilidade objetiva e esta só pode ser conhecida concreta e objetivamente enquanto situada numa totalidade. Por isso, não há modelos uniformes de revolução. 
É no Pequeno Tratado Brasileiro da Revolução e na descrição dos princípios já referidos que Guerreiro Ramos desenvolve os aspectos teóricos e críticos dos processos revolucionários.

Os grandes temas políticos que desenvolveu no Tratado foram: internacionalismo e a revolução, decisão política e determinismo econômico, o ineditismo da época contemporânea, a atitude revolucionária, a situação revolucionária, modelos da revolução, circulação de elites, a derrocada e revolução assumida. Todos os temas giram em torno da realidade brasileira e suas contradições históricas, que emergem nas reconfigurações das classes operárias urbanas e nos conflitos e lutas dos trabalhadores no campo nas décadas de 1950 e 1960 no Brasil. Do mesmo modo, com estilo, desenvoltura e clareza, confronta a situação à luz de teóricos e protagonistas dos processos revolucionários no plano internacional, como Lênin, Marx, Lukács, Che Guevara, Trotsky, Mao Tsé Tung, articulando a partir desses personagens os desafios e limites, principalmente as mais importantes revoluções em curso, a Cubana, a Chinesa e a Soviética. Constrói aspectos situacionais das elites e o poder, frente aos processos revolucionários; o significado dos modelos de revolução. Faz uma distinção entre "derrocada" e "revolução assumida": "A derrocada é fruto da extrema rigidez nas relações entre a classe dominante e as outras classes e, por consequência, da inviabilidade de acomodação pela circulação de elites, de interesses em luta, seja em virtude do esgotamento das possibilidades reais do sistema". (Guerreiro Ramos, 1963, p. 56, 57).

[...] revolução assumida é aquela que um círculo dominante realiza atendendo a reivindicações de camadas sociais radicalizadas, mas no interesse do desenvolvimento de possibilidades contidas ainda no vigente sistema econômico-social (Guerreiro Ramos, 1963, p, 59)

Como já mencionamos, a obra Mito e Verdade da Revolução Brasileira foi publicada em 14 de julho de 1963, portanto, a oito meses do golpe militar de 1964. Guerreiro assumiu o mandato de deputado na Câmara em agosto de 1963 e, no mês de abril de 1964, foi cassado pelo regime militar, instaurado em 31 de março de 1964. O clima político 
social, cultural e econômico era nutrido pelas disputas de classes e interesses, guiados pelo populismo desenvolvimentista, para Jacob Gorender (1987, p. 15):

Desde os anos 30, industrialização e populismo caminharam juntos, potenciando-se reciprocamente. Sua atuação combinada mudou a face do país, porém chegava o momento em que as contradições acumuladas em trinta anos não tinham saída viável nos quadros do regime político inaugurado pela Constituição de 46. Aqui, o conceito de populismo não se reduz à demagogia e manipulação, aspectos secundários no contexto. O populismo inaugurado por Getúlio Vargas se definiu pela associação íntima entre trabalhismo e projeto de industrialização.

Guerreiro Ramos, no Capítulo VII do Mito e Verdade da Revolução Brasileira, escreveu a "Revolução Brasileira ou Jornada de Otários!", reconhecido como um de seus textos mais polêmicos. Ele faz fortes críticas à esquerda brasileira daquele período, críticas essas que levaram a reflexões e acalorados debates. Criticou as teorias e práticas do marxismo-leninismo, seja na versão soviética, chinesa ou cubana. Afirmava que "[...] temos interpretações do problema brasileiro acomodado à visão soviética, à visão chinesa, à visão cubana. A crise brasileira é também crise de cultura política." (Guerreiro Ramos, 1963, p. 176).

A política externa, do ponto de vista de Guerreiro Ramos, deveria estar diretamente relacionada aos valores da soberania e da realidade nacional. Ao mesmo tempo, deveria estimular novos conhecimentos que pudessem liberar a intelectualidade da servidão conceitual em que o pensamento brasileiro se encontrava. Compreender o Brasil e o mundo contemporâneo na perspectiva própria da história nacional não é imperativo acadêmico, é requisito da existência independente. Guerreiro Ramos (1963, p. 176) tinha profunda convicção da conjuntura: “[...] nenhum intelectual isolado será capaz de formular esse diagnóstico requerido pelas circunstâncias. Só poderá resultar do esforço integrado e cooperativo de muitos".

Ao analisar a crise brasileira naquele período (início da década de 1960), escreveu que 
[...] a atual crise brasileira, malgrado os seus efeitos deteriorantes no domínio econômico, financeiro e social, até agora não gerou polarizações agudas que permitam surgir um movimento revolucionário adulto do ponto de vista da organização, da ideologia e da liderança. Até esta data o que caracteriza esse movimento é a imaturidade, que o tem exposto invariavelmente à frustração. A vigente estrutura social tem assimilado as crises nas relações de classe. (Guerreiro Ramos, 1963, p. 191)

Foi enfático ao afirmar que

[...] a revolução brasileira será mistificada, se e enquanto os que pretendem representá-la e servi-la não se desvencilharem de fetiches verbais. A revolução brasileira hoje está diante do dilema: mito ou verdade. Aos otários, - o mito. Façamos a revolução - segundo a verdade da história nacional. (Guerreiro Ramos, 1963, p. 191)

O golpe militar de 1964 aconteceu no dia 31 de março, quando o presidente João Goulart foi impedido de exercer seu governo constitucional e forçado a deixar o país por uma Junta Militar que tomou o poder. O pano de fundo que leva à indispensável avaliação da conspiração civil e militar está marcado pelo desenvolvimento dependente e os interesses específicos do capital internacional e nacional. Outra forte "razão" para o golpe foi o aumento significativo das mobilizações de setores anteriormente marginalizados da população, que não participavam do processo ativo da cidadania brasileira. Sindicatos rurais e ligas camponesas formaram-se em regiões agrícolas, trabalhadores urbanos organizaram-se no interior da estrutura sindical oficial ou em movimentos paralelos que estenderam sua coordenação por diferentes categorias; o governo Goulart buscava o apoio dos trabalhadores, permitia o desenvolvimento de formas de organização mais profundas e efetivas; a descentralização do sistema econômico e político deu aos estados real autonomia decisória. Os exemplos com Miguel Arraes, no estado de Pernambuco, e Leonel Brizola, no Rio Grande do Sul, refletem a construção de um possível desenho de pacto federativo.

Essa "totalidade" dos acontecimentos que institucionalmente vieram sendo marcados desde a Constituição de 1946, de um lado, por 
ser mais democrática que as anteriores, permitiu avanços organizativos da sociedade, e por outro, o desenvolvimento das forças produtivas e o acirramento das contradições de um capitalismo dependente, que mobiliza diversos setores da burguesia que protagonizam o golpe em 1964.

\section{A Sociologia "em mangas de camisa" - o Mandato Parlamentar}

O curto mandato de Deputado Federal do sociólogo Guerreiro Ramos (agosto de 1963/ abril de 1964), se caracterizou pela crença no projeto "popular e nacional", síntese da interpretação política do seu profundo conhecimento sobre a realidade brasileira, dos mais de setenta pronunciamentos (Azevedo; Albernaz, 2013) que fez na Câmara. Seu destino principal era a organização do partido, PTB, críticas ao Partido Comunista Brasileiro e os temas nacionais, acentuando as críticas aos "entreguistas do projeto nacional", "pelegos do nacionalismo" estes, "inimigos" do "projeto emancipador" (Ramos, 1960). No parlamento, expressava a agudeza das suas convicções de sociólogo existencialista e humanista. Estava convencido de que a esquerda comunista (PCB) desenvolvia uma interpretação equivocada da realidade nacional e o trabalhismo apresentava esgotamentos no projeto transformador, caracterizados pelo populismo e o personalismo político.

Na sua campanha, em 1962, chama atenção a três compromissos de campanha, coerentes com o que formulou e defendia como projeto para o desenvolvimento nacional: a participação dos trabalhadores na programação e nos resultados do desenvolvimento econômico, "nacionalização imediata das concessionárias estrangeiras de serviço público" e a realização da reforma agrária (Azevedo; Albernaz, 2013)

Fica evidente nos seus pronunciamentos o que melhor fazia como sociólogo e polemizador acerca dos problemas nacionais. O político, agora com um mandato, estava por melhor se manifestar. Não foi possível, cassado pelo governo militar com a publicação do Ato Ins-

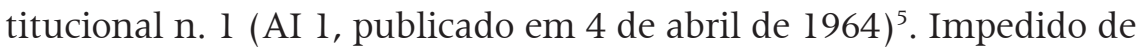
continuar o mandato popular, ele se exilou, embarcando para os EUA 
(Los Angeles, Califórnia) (Lupi, 1995). O Brasil e os brasileiros vivem por vinte anos sob o domínio da ditadura militar.

\section{Conclusão}

Guerreiro Ramos foi sempre muito crítico ao que chamava de "sociologia importada". Referia-se aos padrões e concepções que as ciências sociais assumiam no Brasil. Do mesmo modo e com igual intensidade, criticava a "antropologia da negritude" do seu tempo, culturalista, temerosa em enfrentar a questão das relações de poder (Maio; Santos, 1996). Para ele, se não há raças, o que é verdade, há relações raciais. "O negro é povo no Brasil", afirmava Guerreiro Ramos (1995). Teorias e a verificação da realidade possibilitaram às gerações subsequentes saírem da pantanosa situação das visões culturalistas, anômicas e dos falsos caminhos da democracia racial. Alberto Guerreiro Ramos enfrentou, como poucos no seu tempo, temas que estão na pauta da sociedade contemporânea, dos governos, da política e das ciências sociais: o desenvolvimento, as relações raciais, a economia política, o papel do Estado e das instituições, as transformações sociais, seus conflitos e contradições. Foi um autêntico cientista social, polêmico, criativo, audacioso. Por isso, intérprete singular da realidade social brasileira.

Nesse aspecto, Mito e Verdade da Revolução Brasileira, foi produzido com requinte de análise sobre a "ossatura" do processo revolucionário em curso na década de 1960, capaz de provocar polêmicas diante do que parecia ser fato. A partir do seu ponto de vista, não conseguia enxergar um caminho vitorioso, tendo à frente lideranças que conduziam os processos, dados os "vícios" teóricos e o pouco conhecimento da realidade social brasileira. Escreveu: "Sob o signo do drama de Ionesco, escrevi este livro. Nele trato da metafísica da revolução. No Brasil, a revolução corre o risco de tornar-se façanha rinocerôntica. Reajamos enquanto não é tarde" (Ramos, 1963, p. 13). A metáfora dos anos de 1960 ilumina a realidade brasileira do século XXI. 


\section{Notas}

l Sociólogo - Núcleo de Estudos Negros (NEN)

2 No livro Mito e Verdade da Revolução Brasileira, Guerreiro Ramos desenvolve o que denominou de grupo e lideranças (IBESP e ISEB) intelectuais do movimento nacionalista, que conseguia "empolgar a juventude universitária e a intelectualidade mais válida do País, tornando marginais os círculos pecebistas." (Ramos, 1963, p. 10).

3 Sobre o pensamento político autoritário, ver Simon Schartzman (2007).

4 A concepção de método (crítico-assimilativo, consciência crítica) estão fortemente caracterizados nos escritos da Cartilha Brasileira do Aprendiz de Sociólogo (1954), republicada em Introdução Crítica à Sociologia Brasileira (1957) e no livro A Redução Sociológica (1958), onde descreve sete pressupostos para elucidar a sua compreensão sobre as definições de redução sociológica: a atitude metódica; a não admissão a existência na realidade social de objetos sem pressupostos; postula a noção de mundo; e perspectivista; seus suportes são coletivos e não individuais; é um procedimento crítico assimilativo da experiência, redução sociológica é atitude altamente elaborada (Guerreiro Ramos, 1996, p. 72-73).

5 O Ato Institucional n. 1, que cassa o mandato do Deputado Federal Alberto Guerreiro Ramos, publicado no Diário Oficial da União (DO), em 14 de abril de 1964 (página 3.313), informava que a partir daquela data estavam "suspensos os direitos políticos do professor e servidor público" Guerreiro Ramos (Azevedo; Rabat, 2012).

\section{Referências}

\section{AZEVEDO, Ariston; ALBERNAZ, Renata. Estado, Organização e} Pensamento Social Brasileiro. [S.l.]: EdUFF, 2013.

FERREIRA, Jorge. O Imaginário trabalhista: getulismo, PTB e cultura política popular 1945-1964. Rio de Janeiro: Editora Civilização Brasileira, 2005.

GORENDER, Jacob. Combate nas Trevas, a esquerda brasileira: das ilusões perdidas à luta armada. 3. ed. [S.l.]: Ática, 1987.

GUERREIRO RAMOS, Alberto. A redução sociológica. Rio de Janeiro: Editora UFRJ, 1996.

. Introdução crítica à sociologia brasileira. Rio de Janeiro: Editora UFRJ, 1995.

. Mito e verdade da revolução brasileira. Rio de Janeiro: Zahar Editores, 1963.

HOLANDA, Sérgio Buarque. História geral da civilização brasileira:

o Brasil Republicano, economia e cultura (1930/1964). Rio de Janeiro: Editora Bertrand Brasil, 1980. 
MAIO, Marcos Chor; SANTOS, Ricardo Ventura. (Org.). Raça, Ciência E Sociedade. [S.l.]: Editora Fiocruz; Centro Cultural Banco do Brasil, 1996.

OLIVEIRA, LUCIA LIPPI, A Sociologia do Guerreiro. Rio de Janeiro:

Editora da UFRJ, 1995.

SHAWARTZMAN, Simon. Contribuição de Guerreiro Ramos para a Sociologia Brasileira. Revista de Administração Pública, Rio de Janeiro, p. 30-34, junho, 1983.

SCHWARCZ, Lilia M.; STALING, Heloisa M. Brasil: uma biografia. [S.l.]: Companhia das Letras, 2015.

Recebido em 22/03/2016

Aceito em 19/04/2016 